\title{
Value Creation and Sustainability: Lessons from Leading Sustainability Firms
}

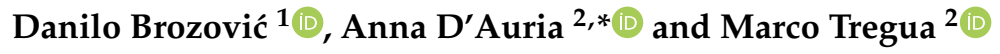 \\ 1 School of Business, University of Skövde, Högskolevägen 8, SE-54128 Skövde, Sweden; \\ danilo.brozovic@his.se \\ 2 Department of Economics, Management, and Institutions, University of Naples Federico II, Via Cintia, \\ Campus Monte S. Angelo, FL IT-80126 Naples, Italy; marco.tregua@unina.it \\ * Correspondence: anna.dauria@unina.it
}

Received: 11 March 2020; Accepted: 29 May 2020; Published: 30 May 2020

\begin{abstract}
The aim of this paper is to chart the value creation process of firms excelling in sustainability. To accomplish this goal, we devise an analytical framework based on a review of the literature combining value creation in service-dominant logic (SDL) and sustainability. We then use the framework to analyze the practices of 100 firms excelling in sustainability, so as to offer a contribution in the form of a combination of insights from practice and theoretical analysis portraying the service ecosystem incorporating sustainability. The double-step analysis highlighted the relevance of a multi-actor perspective as a driver for the incorporation of sustainability in the value creation process, as well as the relevance of actors' participation in firms' processes, such as in resource integration and in line with the aim of sustainable service provision. The results advance the understanding of the elements of SDL as well as how the interplay among them occurs from a sustainability-based perspective.
\end{abstract}

Keywords: sustainability; value creation; service-dominant logic; institutions; actors

\section{Introduction}

Firms are increasingly adapting their activities within a more sustainable approach, due to both stronger sustainability requirements and the implementation of innovation in the form of new technologies and tools aimed at improving the environmental, social, and economic impacts of businesses. In this regard, supranational and intergovernmental organizations, such as the United Nations [1,2], as stressed in Torres-Rahman et al. [3], and the European Commission [4], provide tools and guidelines through which firms can achieve sustainable development goals, as suggested by Brundtland et al. [5]. These efforts were recently acknowledged by Forbes [6] in its "The Global 100" ranking of large companies excelling in sustainability combined with high revenues. The ranking attracted the attention of a wide audience because it offers a series of relevant insights into large firms' success in sustainability, especially firms in industries commonly perceived as being not eco-friendly, e.g., the automotive, oil, and telecommunication industries.

However, the focus of this ranking is only partially mirrored in current studies in the domain of service research and sustainability, as several studies are centered either on sustainability independently (e.g., [7]) or on how sustainability is marketed (e.g., [8]). Although service research scholars have devoted attention to the linkage between sustainability and the processes of large firms from a theoretical angle (e.g., [9-11]), few studies reflect how the value creation process could incorporate sustainability (e.g., [12,13]). This gap between practice and research in value creation has been recently highlighted by Vargo and Lusch [14] as well. 
Following the latter highlight from service-dominant logic (SDL) scholars, service research has been considered a suitable theoretical framework for investigating sustainable value creation [15] because the theoretical developments focusing on value creation are useful in describing the contributions of and consequences for all the actors shaping service ecosystems incorporating sustainability [14,16-18]. For example, previous research intertwining SDL and issues of sustainability has focused on actors frequently addressed and represented as stakeholders (e.g., [17,19,20]), explored issues involving resource integration (e.g., [18,21]) and service exchange (e.g., [22]) in such service ecosystems, and discussed institutions and institutional arrangements (e.g., [23]) or value co-creation in general (e.g., $[16,24]$ ) in service ecosystems incorporating sustainability. Contributions combining sustainability and value creation from an SDL perspective have stimulated scholars' interest and set the ground for the proposal of empirical studies to observe the ongoing changes in firms' choices and behaviors (e.g., [16])

Consequently, this article aims to investigate how firms shape the value creation process while simultaneously incorporating sustainability into this value creation process; additionally, we offer a clarification of the actors, the resource integration process, and the institutional arrangements supporting this process. To do that, we first devise an analytical framework based on a review of the literature combining value creation in SDL and sustainability. We then use this framework to analyze the practices of the 100 firms mentioned above in order to offer a fresh contribution combining theoretical analysis and a detailed investigation of firms whose performance excels in terms of addressing sustainability as a key goal. The analysis is followed by implications for both scholars and managers, as well as by elements suggesting avenues for future research in this domain.

\section{Theoretical Overview}

The overall theoretical lens of SDL is based on defining service as the basis of all economic exchange [25]. More recently, SDL propagated the service ecosystems perspective and encapsulated it in the so-called narrative of SDL-value co-creation is placed in the center of the service ecosystem consisting of actors who are involved in resource integration and service exchange enabled and constrained by endogenously generated institutions and institutional arrangements [14]. (The narrative has been applied previously in research merging SDL and sustainability; see, e.g., [16].) Moreover, SDL has proven to be relevant in discussions on sustainability [14,16-18]. The rest of this section provides on overview of how this narrative-the actors, resource integration, service exchange, institutions, and value co-creation-has been reflected in extant research merging SDL and themes of Corporate Social Responsibility (CSR; e.g., [26]), sustainability (e.g., [27]), green marketing (e.g., [28]), and ethics (e.g., [24,29]). The latter topics approach sustainability from various disciplines, which is not uncommon in research merging sustainability and SDL (see, e.g., [16-18]). In line with this research, we recognize that sustainability must be identified from a wider point of view and that it leads to the balancing of economic, social, and environmental goals [11,17]. These three goals are the common denominator tying together sustainability, CSR, and green marketing.

The contributions constructing this literature overview have been selected in a systematic fashion. Following the purpose of the manuscript, we have searched for articles about sustainability, green marketing, CSR, and, to some extent, ethics, when articles within these topics used or referred to SDL and, particularly, Vargo and Lusch (2004). The requirement for the search was that either "sustainability", "CSR", or "green marketing" should be contained in the title, abstract, and/or keywords, and simultaneously use and/or mention SDL or value co-creation. The search was conducted in Web of Science, Emerald, Scopus, and Google Scholar. After eliminating duplicates, we identified totally 67 articles fulfilling these criteria. The next step was reading the articles using the elements of the narrative of SDL as a lens to frame their content and contributions, and in this manner to understand the main insights from the literature merging sustainability and related topics with SDL. We continue with accounting how relevant identified contributions relate to the narrative of SDL in order to flesh out main theoretical insights on service ecosystems incorporating sustainability. 
Discussing actors, previous literature merging value co-creation and sustainability predominantly portrays the process of value co-creation emerging in service ecosystems of multiple actors, which, in the sustainability-related literature streams, are frequently referred to as stakeholders. (In SDL, the preferred term is "actors", which encompasses stakeholders, but is broader in its essence.) For example, early on, Maignan et al. [20] portrayed systems of multiple actors with CSR and ethics at its core. Moreover, Sebhatu and Enquist [26] extended Edvardsson and Enquist's [30] concept of "values-based value creation" (see also [31]) to argue for a transformation of organizational actors by the incorporating of a culture led by values such as ethics, sustainability, and CSR. The authors claimed that this incorporation enables higher levels of sustainability during value co-creation. This is confirmed by the suggestion that CSR activities perceived as philanthropy will create more ethical value for consumers who are self-transcended, though not for consumers who are self-enhancing [32]. Moreover, it is actors' interactions that synergistically lead to the creation of economic, social, and environmental value [17]. One tool that could help transform actors' values is education about the human-environment interface and a shift in marketing from promoting the acquisition of goods to including other aspects of value where SDL can be helpful [28]. In addition, the values and culture of the actors influence their perceptions and, in turn, value co-creation [33,34]. More concretely, some authors suggested that SDL should be updated with the inclusion of a fundamental premise that "value is determined by values" [35]. Essentially, previous literature has adopted multi-actor perspective and explored some of the motives and perceptions.

Such multiple actors are driving processes of resource integration, creating value for all the actors and not necessarily corporate actors. For example, research has identified service ecosystems (or networks) incorporating sustainability where social entrepreneurs develop sustainability-aimed innovation to drive value co-creation for the involved parties [36]. Furthermore, recent research confirms that value co-creation strategies give birth to different types of innovation, including social and sustainable innovation [18]. Other resources behind such service ecosystems have been suggested-for example, social capital, reputation, and trust [37] or learning through relationships in a complex service ecosystem incorporating sustainability [38]. Further, extant research has been interested in understanding the mechanisms of value creation for multiple actors [21]. Essentially, previous studies were interested mostly in the mechanisms of resource integration in service ecosystems incorporating sustainability.

Furthermore, some researchers have been occupied by efforts to understand how service is exchanged when service ecosystems incorporate issues of sustainability. Service exchange is the economic motive stimulating and activating interactions among entities in service contexts [39], as it is aimed at providing a benefit to customers or to entities in the interactions [40,41]. For example, service exchange can be treated as the basis of any exchange, whether human or natural [22]. Value propositions in the form of, for example, CSR initiatives started by actors such as corporations can also contribute to service exchange and value co-creation in service ecosystems [42]. Additionally, social enterprises and their socially aimed value propositions can help increase the level of service exchange aimed at sustainability within a service system incorporating sustainability [43]. Further, some authors have suggested imbuing service exchange with sustainability to increase the level of sustainable development in a service system incorporating sustainability [44]. All in all, researchers were attempting to bring more clarity to the process of service exchange in service ecosystems incorporating sustainability.

Most of the research on service ecosystems incorporating sustainability has been conducted on institutions and institutional arrangements. Institutions have been defined as rules, norms, meanings, symbols, and practices within a service ecosystem, and institutional arrangements as independent assemblages of institutions [45]. For example, ethics has been deemed as an implicit basis of co-creation [24,29]. Ethics is present not only in CSR but also in other aspects driven by value co-creation, according to this author. Indeed, it is claimed that service is inherently ethical [46]. Other authors have also suggested that ethics is the fundamental part of value co-creation [47], that responsible marketing has its foundation in ethical principles and actions, which are inherently co-creational [48], and that ethical values influence the decisions of actors participating in service 
ecosystems incorporating sustainability [49]. Ethics is particularly suitable because it creates a symbiotic relationship between the internal organization and its external environment [50]. Thus, ethics arises as the fundamental institutional arrangement of service ecosystems incorporating sustainability.

Regarding value co-creation, value should include not only economic (financial) value but also social value and environmental value [51]. Normann and Ramírez [52] postulated that value does not necessarily have to be financial but can include other types of value, such as social value and knowledge. Social value is the social dimension of CSR [34]. Some researchers advocated for the so-called environment-dominant logic, arguing that value should include environmental value [28]. This notion was implicitly explored in more detail as a means of seeking parallels between human-made service and natural services [22]. It was also posited that value co-created in the service ecosystem of a group of actors who are simultaneously beneficiaries does not necessarily have to contradict the cause or greater good $[53,54]$. More concretely, value emerging in a service ecosystem incorporating sustainability is economic, social, and environmental [17].

In short, a service ecosystem should include and assist in the value co-creation of all the actors and not only customers [55]. In addition, value flows within a service ecosystem can be pre-designed into the ecosystem [56,57]. Indeed, research confirms at least three orientations to value creation-namely, consumer, institutional, and environmental [58]. Thus, previous research identified types of values and the actors at whom these types are aimed, with the ultimate goal being to understand value flows in service ecosystems incorporating sustainability.

The purpose of service ecosystems incorporating sustainability is mirrored in their complexity; such service ecosystems address issues far larger for a single actor or a pair of actors in partnership, with ecological challenges being the obvious example [38]. One aspect of these more-inclusive service ecosystems is their inherently democratic nature [59] due to considerations expressed toward and between multiple actors, the service exchanges between them, and the value flows in such a service ecosystem incorporating sustainability. Indeed, actors share the purpose of viable value co-creation occurring in viable ecosystem-based resource integration [60]; this viability is achieved by dealing with complexity as an innate feature of service contexts shaped by multiple actors, intertwined actions, and enablers of actors' behaviors [61].

To conclude, based on the narrative of SDL [14] and the overview of the literature intertwining SDL and sustainability, we develop the following analytical framework.

\section{Methodology}

To answer the research questions highlighted above and to deal with the main issue of this paper, namely, to understand the value creation process occurring in a service ecosystem incorporating sustainability, we adopted a qualitative approach because of the nature of the topic. Indeed, previous studies on firms' sustainability in the value co-creation process adopted a qualitative approach due to the lack of previous investigations into sustainable service ecosystems [14]. Additionally, a qualitative approach is suitable for considering the research questions proposed above, due to the different angles from which sustainability is observed and because of the need to describe some issues in more detail. More specifically, our approach is deductive because we aim primarily to support existing theories and conceptualizations [62].

The research context consists of 100 firms excelling in sustainability combined with excellent financial performance, based on the ranking proposed by Forbes in 2019 [6] compiled by a Canada-based sustainability-focused financial information company, Corporate Knights [63]. This report ranks large corporations across the globe based on their performance in reducing carbon and waste, their gender diversity among leadership, their revenues derived from clean products, and their overall sustainability [6]. Moreover, paying attention to firms adopting sustainability-oriented practices and being recognized as a role model for several industries are features of previous studies on sustainability (e.g., [64]). The adoption of a focus on these firms provides additional support for the choice of a qualitative approach because the differences in size, geographical area, industry, and firms' age make 
the sample too heterogeneous for investigation by use of a quantitative approach; indeed, a qualitative approach would support the understanding of specific features representing industries, countries, or certain typologies of firms, leading to a more careful description of the value co-creation process in different scenarios.

The research approach applied was the content analysis of sustainability reports. This approach is in line with the purpose of the article, as it corresponds with the careful analysis of practical approaches to sustainability in the value co-creation process. The content analysis approach is essentially a structured and systematic examination of certain communication material [65] —in our case, sustainability reports-and can be used to describe a phenomenon following a set of categories [66]. The main strength of such a content analysis is to support-and, in certain cases, extend-theoretical insights $[62,66]$. Furthermore, content analysis as we apply it helps us make sense of the qualitative data and identify core consistencies and meanings [62].

\section{Research Design}

The research process was initiated by defining a set of categories used for the content analysis of the phenomenon of service ecosystems incorporating sustainability—basically, our theoretical framework presented in Table 1-and collecting the data. The data consisted of the sustainability reports from 100 pre-defined firms. The analysis started with the assignment of five random sustainability reports to each researcher, who then performed an independent content analysis according to the categories in the framework, using the Weft QDA software. After this initial round of analysis, the preliminary findings were distributed between the researchers and re-analyzed by the other researchers. Discrepancies arising in this round of analysis were dealt with during several discussion rounds, in which opinions and impressions were shared to reduce bias and reach homogenous analysis results.

Following this initial analysis round, the data set was divided equally between the researchers and the rest of the analysis was performed. After the main analysis round, results concerning five firms other than those in the initial data set were shared between the researchers and analyzed additionally to ensure the stability of the final results. This additional analysis round showed some discrepancies, though nothing that would jeopardize the quality of the findings.

The choice of the content analysis approach mirrors previous investigations dealing with sustainability (e.g., [67]) and favors the depiction of multiple ties among the research questions we set. Additionally, the contents to be analyzed are not based on a huge amount of data [68], as the description of firms' value co-creation processes is not particularly illustrative. Finally, the use of quotations supports theoretical insights and provides concrete examples of what businesses are doing to make their value co-creation processes sustainable.

From a practical point of view, the findings presented in the next section are based on the methodological suggestions by Deacon [69]. In more detail, Deacon suggested using content analysis to avoid low-level omissions. We find this suggestion useful as a means of avoiding missing the mechanisms of the value creation process. The next section provides the findings, primarily describing the content analysis's phenomenon of interest [65] and supporting - and, in some cases, extending - the theoretical insights [66]. The results of the analysis provide valuable insights into how firms deal with value creation and sustainability. More often than not, these insights do not focus on a single theme but, rather, emphasize the embedded interconnectedness of the themes and reflect value creation strongly ingrained with sustainability as the ultimate outcome of service ecosystems incorporating sustainability. However, we must emphasize that the quality of the findings depends largely on what firms chose to emphasize.

In the next section, we present representative illustrative examples of firms excelling in value creation and sustainability, grouped under the themes of the SDL narrative. 
Table 1. Narrative of service-dominant logic (SDL) and research questions.

\begin{tabular}{|c|c|c|c|}
\hline The Narrative of SDL & $\begin{array}{l}\text { Adaptation Reflecting a } \\
\text { Service Ecosystem } \\
\text { Incorporating Sustainability }\end{array}$ & Insights from the Literature & Research Questions (RQs) \\
\hline \multirow{3}{*}{ Actors } & \multirow{3}{*}{ Multi-actor perspective } & $\begin{array}{l}\text { Multiple stakeholders, who are not } \\
\text { necessarily corporate actors. }\end{array}$ & \multirow{3}{*}{$\begin{array}{l}\text { Who are the actors in a service } \\
\text { ecosystem incorporating } \\
\text { sustainability? } \\
\text { What are their motives, } \\
\text { perceptions, and perspectives? }\end{array}$} \\
\hline & & $\begin{array}{l}\text { The service ecosystem supports the } \\
\text { value creation of consumer, } \\
\text { institutional and } \\
\text { environmental actors. }\end{array}$ & \\
\hline & & $\begin{array}{c}\text { Values and cultures of actors influence } \\
\text { their perceptions and, in turn, } \\
\text { value creation. }\end{array}$ & \\
\hline \multirow{2}{*}{ Resource integration } & \multirow{2}{*}{$\begin{array}{l}\text { Mechanisms and drivers of } \\
\text { resource integration }\end{array}$} & $\begin{array}{l}\text { A shift from the acquisition of goods } \\
\text { to include other aspects of value. }\end{array}$ & \multirow{2}{*}{$\begin{array}{c}\text { How are resources integrated in } \\
\text { service ecosystems incorporating } \\
\text { sustainability? }\end{array}$} \\
\hline & & $\begin{array}{l}\text { Some mechanisms: social } \\
\text { entrepreneurship and innovation. }\end{array}$ & \\
\hline \multirow{3}{*}{ Service exchange } & \multirow{3}{*}{$\begin{array}{l}\text { Understanding the process of } \\
\text { a service ecosystem } \\
\text { incorporating sustainability }\end{array}$} & $\begin{array}{l}\text { A broader understanding of service } \\
\text { encompassing human and } \\
\text { natural services. }\end{array}$ & \multirow{3}{*}{$\begin{array}{l}\text { How is service exchanged in } \\
\text { service ecosystems incorporating } \\
\text { sustainability? }\end{array}$} \\
\hline & & $\begin{array}{l}\text { The role of CSR initiatives and social } \\
\text { enterprises in increasing the level } \\
\text { of exchange. }\end{array}$ & \\
\hline & & $\begin{array}{l}\text { Imbuing service exchange } \\
\text { with sustainability. }\end{array}$ & \\
\hline \multirow{3}{*}{$\begin{array}{l}\text { Institutions and } \\
\text { institutional } \\
\text { arrangements }\end{array}$} & \multirow{3}{*}{$\begin{array}{l}\text { Values and ethics as } \\
\text { institutions of service } \\
\text { ecosystems } \\
\text { incorporating sustainability }\end{array}$} & $\begin{array}{l}\text { Ethics as the fundamental } \\
\text { institutional arrangement. }\end{array}$ & \multirow{3}{*}{$\begin{array}{l}\text { What institutions lie behind value } \\
\text { creation in service ecosystems } \\
\text { incorporating sustainability? }\end{array}$} \\
\hline & & Values-based value co-creation. & \\
\hline & & $\begin{array}{l}\text { Sustainability and CSR as } \\
\text { additional institutions. }\end{array}$ & \\
\hline \multirow{2}{*}{ Value co-creation } & \multirow{2}{*}{$\begin{array}{l}\text { Economic (financial) value, } \\
\text { social value, environmental } \\
\text { value, value for the actors }\end{array}$} & $\begin{array}{c}\text { Value is not only financial but also } \\
\text { includes other aspects of value (social } \\
\text { value, environmental value). }\end{array}$ & \multirow{2}{*}{$\begin{array}{c}\text { What types of value are created in } \\
\text { service ecosystems incorporating } \\
\text { sustainability? At which actors are } \\
\text { they aimed and why? }\end{array}$} \\
\hline & & $\begin{array}{l}\text { Consumer, institutional, } \\
\text { and environmental actors and the } \\
\text { corresponding types of value. }\end{array}$ & \\
\hline
\end{tabular}

\section{Findings}

In the section delineating the research framework, our perspective stems from the basis of what emerged from the analysis of literature contributions. The insights from literature let us identify how the narrative of SDL is reflected in the service ecosystems incorporating sustainability. Based on the theoretical overview, we developed a set of RQs and used them to analyze the behavior of the most sustainability-oriented companies as suggested by Forbes and Corporate Knights.

An empirical analysis, through a manual content analysis, as suggested by Deacon [69], was performed on the sustainability reports provided by the companies listed in the Corporate Knights ranking [63]. Analysis of the reports led us to identify several common elements between scholars' perspectives and companies' initiatives. In general, most of the companies paid particular attention to environmental and societal development.

In line with the themes emerging from the literature, the findings have been described in five subparagraphs; however, it must be noted that though the results emerging from the analysis of the empirical evidence have been categorized, several connections between them have been observed.

\subsection{Actors}

Regarding actors in service ecosystems incorporating sustainability, the analysis confirms the presence of a multitude of actors, who are largely involved in decision-making processes and committed to spreading sustainability values. These values are frequently considered the basis upon which strategies and initiatives related to sustainability are built. Moreover, the main motive related to sustainability issues behind actors' actions identified by the analysis is increasing the quality of life for 
the majority of actors. The majority of firms emphasize how relationships and partnerships between various actors are necessary to incorporate sustainability in the service ecosystems, especially on the immediate local level. For example, Advantech stated that "the base of a sustainable operation is, seeking the perfect balance between stockholders, employees, customers and society"; meanwhile, the Japanese company Konica Minolta takes particular care regarding relations with investors. In terms of the involvement of actors in the decision-making process and the commitment of the firms to local sustainable development, Pearson claimed that they "are committed to building strong relationships with political and educational leaders (...) share best practices, inform the policymaking process, and forge innovative partnerships aimed at increasing student access, affordability, and success", simultaneously paying attention to the importance of the integration of different intellectual resources as a means of co-creating value. The relevance of relationship building and the connection with all the actors interacting with the company is also stressed by ABB Group, which aims to engage "in meaningful dialogue and collaboration with stakeholders to clarify ABB's positions and policies and, at times, to understand different viewpoints". With a more market-oriented perspective, Total seeks to engage clients in the definition of its strategies, "forging partnerships for and with (our) customers", to offer more innovative and satisfying products and services. Partnerships and relationship building are also stressed by Adidas, underlining the relevance of a connection to the local community as a means of better understanding the needs and cultural sensitivities of that community; "for that reason, (we) regularly partner with local organizations". In this regard, the Japanese company Konica Minolta must be mentioned again; with the aim of preserving both the local community and its employees, the company declares, on its official website, that it implemented special measures to prevent COVID-19 infections by cooperating with local health agencies. Thus, Konica Minolta attempts to increase the quality of life for the majority of the actors in its service ecosystem.

\subsection{Resource Integration}

In terms of the resource integration, the results of the analysis largely confirm implications acknowledged by the literature overview: in service ecosystems incorporating sustainability resources are integrated to include other aspects of value, with sustainability-aimed innovation and, consequently, business models as the main mechanisms. In this aspect, innovation should lead to sustainability in some manner. Interestingly, insights on social entrepreneurship are lacking in the empirical data, perhaps because the data set included for-profit actors.

In addition, the analysis shows that intellectual and technological resources are the most considered ones with respect to the creation of value. For example, the integration of intellectual and technological resources is fundamental to Novartis, engaging professionals and scientists from several sectors to offer high-quality products and contribute to scientific and medical research for the improvement of health in developing and poor countries. This integration of technological and intellectual resources within business model as a resource integration mechanism that Novartis refers to is also described by Accenture, emphasizing a holistic approach "that brings together strategy, design and execution to not only address today's pressing needs, but also take advantage of tomorrow's opportunities".

As already mentioned, innovation leading to sustainability is another mechanism of resource integration in service ecosystems integrating sustainability frequently mentioned by scholars [33], as well as by firms. For example, Panasonic created a division devoted to Manufacturing Innovation in a sustainable way, as it is "working to reduce energy consumption to use in our factories, through multiplying our strength in manufacturing, with 'Manufacturing Vision' which aims at trying to solve customer issues and social issues". Innovation initiatives have an impact on both the economic and social spheres and, in the long term, on sustainable development. In its last sustainability report, Chr. Hansen Holding $\mathrm{A} / \mathrm{S}$ stated that its mission is "Innovating for a sustainable future"; in fact, many innovative initiatives aim to improve the environmental impacts of business activities. A similar approach is adopted by Accenture, which regards innovation as a tool with which to create a truly inclusive workplace. The tie between innovation and business models for sustainability and resource integration is also 
stressed by Iberdrola, a Spanish company in the energy industry and a leader in renewable energies. Indeed, the company stated that it collaborates "with a number of universities and institutions in the universalisation of energy services, as well as in driving knowledge in specific scientific, energy and IT areas thanks to an open and de-centralised RED management model". Together, these examples show that firms integrate technological and intellectual resources with the help of business models and innovation, in partnership with multiple actors.

\subsection{Service Exchange}

As a tool for improving quality of life, service is a concept usually associated with people and, more in general, with the social sphere. Our theoretical overview exhibited how the literature on service ecosystems incorporating sustainability extends service to in some cases include even natural services [22]. However, our analysis does not show the latter perspective present in the data. On the other hand, the analysis confirms that CSR initiatives increase the level of service exchange and that the exchange is imbued with sustainability. Expanding the theoretical insights, the analysis reveals interaction and collaboration as primary mechanisms of service exchange in service ecosystems incorporating sustainability.

One example of how CSR initiatives could increase the level of service exchange is HP, that, in the provision of services and products, applies "strong ethics and anti-corruption principles within our operations, across our value chain, and in the communities where we live, work, and do business"; likewise, Kering focuses on the interaction among stakeholders and between the company and stakeholders, stating that its commitment is "to fostering dialogue and interactions with and between its stakeholders (...). These exchanges fully contribute to a global and shared value creation (... ) by stages in the value chain". The goals pursued by HP and Kering also show that these firms pay attention to actors as well as value co-creation, aimed at improving both social and economic conditions for several categories of stakeholders.

The role of collaboration is exemplified by Swedish company Electrolux, which stressed the role of sharing vision and promoting more sustainable initiatives throughout the supply chain. This led the firm to act as a promoter of sustainability when sharing "best practice in transport management. (...) with a commitment to reduce road transport-related emissions" and as a controller of the activities run by partners when evaluating "the environmental performance of logistics suppliers". Collaboration for sustainability is also pursued by ABB Group, which, in its last sustainability report, declared that "ABB actively encourages and supports innovation by collaborating with leading technical institutes and universities, and by investing in and working with innovative startups".

\subsection{Institutions and Institutional Arrangements}

Considering institutions and institutional arrangements, ethics are both in the literature and according to our findings main institution in service ecosystems incorporating sustainability. In addition, sustainability and CSR can be considered additional institutions, leading the actions of firms in their performance [44]. This insight about CSR and sustainability as contributing to institutions is present both in the literature and in the findings as well. However, the most interesting result of the analysis shows that firms in our data set highly value formalized institutions in the form of laws, regulations, certificates, international standards, and other guidelines. The reason behind this high importance of formal institutions is most probably increased legitimacy of firms' sustainability efforts and initiatives that this formality can provide.

For example, firms such as the American Tesla and Danaher, the Italian Intesa San Paolo, and CapitaLand from Singapore have declared that they operate in compliance with international regulations and guidelines to reduce the environmental impact of their businesses and to contribute to local and global sustainable development, respecting all the companies' stakeholders. In more detail, Tesla stated that it follows the Waste Batteries and Accumulators Regulations 2009 and added that one of its factories "was certified as a "Zero Waste" facility," as well as that the company "was recognized for 
our commitment to recycling and product reuse". Meanwhile, Danaher encourages employees to report any violations stated in its Code of Conduct, while Intesa San Paolo follows the UNEP FI Principles for Responsible Banking (PRB), "aimed at promoting dialogue between companies, international organizations and society and to pursue respect for the environment and human rights". CapitaLand follows the GRI Guidelines, being one of the first companies to voluntarily adopt them, stating that "[f]or external stakeholders, priority is given to issues important to the society and applicable to CapitaLand". The GRI Guidelines and 231 Organizational Model have also been adopted by Ecolab, "with the aim of building $a$ structured system of guiding principles and operating procedures".

One particular institutional arrangement we identified in the analysis is the assemblage of formal and informal institutions, with ethics, CSR, and sustainability as the common denominators between these two types of institutions. For example, the recycling and product reuse initiatives pursued by Tesla underpin shared values and a culture oriented toward sustainability, thereby encouraging efforts aimed at creating value and improving the quality of life of people as well as improving environmental conditions.

\subsection{Value Co-Creation}

Both the theoretical overview and the analysis of sustainability reports distinguish between economic, social, and environmental value, with value representing and summarizing the outcomes of value co-creation processes, namely, business activities resulting from the interactions of multiple actors. Thus, value is associated mainly with actors as the recipients of sustainable development initiatives [41] and business activities focused not only on financial issues but also including other aspects of value, such as social value and environmental value $[11,70]$. Concerning the latter, for example, Banco do Brasil operates to "provide sustainable solutions that generate financial returns and bring social benefits", while Samsung "strives to share more values with its stakeholders through the pursuit of balanced growth and stability". With a special reference to environmental aspects, Neste Corporation aims to create "a healthier planet for our children by creating responsible choices every day. Combating climate change is our business".

What the findings bring to the forefront are the aspects of balance and interdependence between these three types of value aimed at different groups of actors. In essence, this balance and interdependence are ingrained in sustainability, explaining that it should lead to the balancing of economic, social, and environmental goals $[11,17]$. Tight ties between financial returns and sustainable value are summarized in the title of the sustainability report issued by Ingersoll Rand, a US company. This report is titled "Performance with purpose" to clarify the multiple sides of value; moreover, the firm stated that "Our people and family of brands [...] work together to create value for customers in homes and buildings, transportation and industrial processes, allowing them to be environmentally responsible and productive at the same time".

The analysis related to issues of value identified especially the philanthropic approach-as established in the literature by Carroll [19]—as a mechanism enabling types of value other than financial to actors in service ecosystems incorporating sustainability. For example, this approach is evident in Ericsson's declaration of commitment to creating value for the whole community. In its last sustainability report, Ericsson stated that "through donations, we engage our employees, fulfill our social responsibilities, and empower our local and regional communities. We seek to donate in areas where long-term effects are predominant and focus on saving lives, fighting discrimination and improving society". A philanthropic approach is also adopted by Alstom, which improved Metro de Santiago trains, thereby creating an inclusive and accessible network that provides more comfortable spaces to people with reduced mobility.

Main findings are summarized in Table 2. 
Table 2. Narrative of SDL and the main insights from the analysis.

\begin{tabular}{|c|c|c|c|c|}
\hline The Narrative of SDL & $\begin{array}{c}\text { Adaptation Reflecting a } \\
\text { Service Ecosystem } \\
\text { Incorporating Sustainability }\end{array}$ & RQs & Main Insights from the Analysis & Representative Quotations \\
\hline Actors & Multi-actor perspective & $\begin{array}{l}\text { Who are the actors in a } \\
\text { service ecosystem } \\
\text { incorporating sustainability? } \\
\text { What are their motives, perceptions, } \\
\text { and perspectives? }\end{array}$ & $\begin{array}{l}\text { Service ecosystem incorporating sustainability consists of a } \\
\text { multitude of various actors (e.g., the firm, clients, employees, } \\
\text { stockholders, and investors). } \\
\text { The main motive behind sustainability measures is increasing the } \\
\text { quality of life for the majority of actors, especially in the } \\
\text { immediate local community. } \\
\text { In addition, perceptions and perspectives of various actors must } \\
\text { be balanced, with the emphasis on relationship building and } \\
\text { partnerships between the actors. }\end{array}$ & $\begin{array}{l}\text { "We are committed to building strong relationships with political and } \\
\text { educational leaders" (Pearson, UK) } \\
\text { "Seeking the perfect balance between stockholders, employees, customers } \\
\text { and society" (Advantech, Taiwan) } \\
\text { "We regularly partner with local organizations" (Adidas, Germany) }\end{array}$ \\
\hline Resource integration & $\begin{array}{l}\text { Mechanisms and drivers of } \\
\text { resource integration (RI) }\end{array}$ & $\begin{array}{l}\text { How are resources integrated in } \\
\text { service ecosystems } \\
\text { incorporating sustainability? }\end{array}$ & $\begin{array}{l}\text { In service ecosystems incorporating sustainability firms integrate } \\
\text { technological and intellectual resources with the help of business } \\
\text { models and innovation, in partnership with multiple actors. }\end{array}$ & $\begin{array}{c}\text { "Partnerships maximise the impact of our efforts to improve nutrition" } \\
\text { (Unilever, UK) } \\
\text { "Innovating for a sustainable future" (Chr. Hansen Holding } \\
\text { A/S, Denmark) } \\
\text { "Co-innovating tomorrow" (Yokogawa Electric Corporation, Japan) }\end{array}$ \\
\hline Service exchange & $\begin{array}{l}\text { Understanding the process of a } \\
\text { service ecosystem } \\
\text { incorporating sustainability }\end{array}$ & $\begin{array}{l}\text { How is service exchanged in } \\
\text { service ecosystems } \\
\text { incorporating sustainability? }\end{array}$ & $\begin{array}{l}\text { CSR initiatives increase the level of service exchange, } \\
\text { and exchanges are imbued with sustainability. } \\
\text { Interaction and cooperation are the main mechanisms of service } \\
\text { exchange in service ecosystems incorporating sustainability. }\end{array}$ & $\begin{array}{l}\text { “Exchanges fully contribute to a global and shared value creation” } \\
\text { (Kering, France) } \\
\text { “We actively encourage a culture of openness, engagement and } \\
\text { communication by integrating messaging on ethics into our business } \\
\text { meetings at all levels" (Spectris plc, UK) } \\
\text { “Collaborating with leading technical institutes and universities" } \\
\text { (ABB, Switzerland) }\end{array}$ \\
\hline $\begin{array}{l}\text { Institutions and } \\
\text { institutional arrangements }\end{array}$ & $\begin{array}{l}\text { Values and ethics as institutions } \\
\text { of service ecosystems } \\
\text { incorporating sustainability }\end{array}$ & $\begin{array}{l}\text { What institutions lie behind value } \\
\text { creation in service ecosystems } \\
\text { incorporating sustainability? }\end{array}$ & $\begin{array}{l}\text { In service ecosystems incorporating sustainability, formalized } \\
\text { institutions in the form of laws, regulations, ertificates, } \\
\text { international standards, and other guidelines are especially } \\
\text { relevant to secure legitimacy in actors' efforts. } \\
\text { Institutional arrangements in service ecosystems incorporating } \\
\text { sustainability are assemblages of formal and informal institutions, } \\
\text { with ethics, CSR, and sustainability as common denominators. }\end{array}$ & $\begin{array}{l}\text { "Pursue respect for the environment and human rights" (Intesa San } \\
\text { Paolo, Italy) } \\
\text { "Building a structured system of guiding principles and operating } \\
\text { procedures" (Ecolab, US) } \\
\text { "Our Labour and Ethics Management System is designed to ensure } \\
\text { compliance with applicable laws, regulations and customer requirements } \\
\text { related to our operations and products" (Celestica, Canada) }\end{array}$ \\
\hline Value co-creation & $\begin{array}{l}\text { Economic (financial) value, } \\
\text { social value, environmental } \\
\text { value, value for the actors }\end{array}$ & $\begin{array}{l}\text { What types of value are created in } \\
\text { service ecosystems incorporating } \\
\text { sustainability? At which actors are } \\
\text { they aimed and why? }\end{array}$ & $\begin{array}{l}\text { Value created in service ecosystems incorporating sustainability is } \\
\text { economic, social, and environmental. These types of value are } \\
\text { aimed at different actors in different occasions, most frequently } \\
\text { via philanthropic activities. } \\
\text { In addition, they are interdependent and they should be balanced. }\end{array}$ & $\begin{array}{l}\text { "The pursuit of balanced growth and stability" (Samsung, } \\
\text { South Korea) } \\
\text { "Fulfill our social responsibilities, and empower our local and regional } \\
\text { communities" (Ericsson, Sweden) } \\
\text { "Electrolux Professional has significant potential for long-term value } \\
\text { creation as an agile stand-alone company, which can pursue growth } \\
\text { through market consolidation and innovation" (Electrolux, Sweden) }\end{array}$ \\
\hline
\end{tabular}




\section{Discussion}

The first consideration emerging from the findings is how commonly the elements of the narrative of SDL are referred to by firms describing their efforts to further their value propositions and make them sustainable. This result may be considered as relevant to further the need to complement theorization with empirical observation; indeed, Vargo and Lusch [14] stressed the need to close the gap between theory and business practices, even with reference to sustainability. Indeed, as witnessed in the analysis of the 100 best in class as ranked by Forbes, firms often use notions such as actors and their relationships; resource integration and the exchange to which it leads; institutions and institutional arrangements such as ethics, sustainability, and CSR; and the processes required to achieve value.

In this regard, most of the previous studies linking SDL and sustainability issues focus on the role of actors and resources as levers for developing value through service exchange (e.g., [20,22]) in line with the service ecosystem perspective. Therefore, at a general level, marketing scholars are paying attention to sustainable development and CSR issues, though there are still few contributions linking SDL, sustainability, and its management [12-14], with special reference to contributions featured by an empirical analysis.

Thus, our analysis favored the emergence of two main results, namely (a) an enriched perspective on the elements of the narrative of SDL in the sustainability debate through the combination of theoretical insights and empirical evidence, and (b) insights into how elements of the narrative inevitably intertwine to achieve sustainable value.

With regard to the enriched perspective, first, we consider actors as not just shaping a context inspired by sustainability [20] but also as contributing to the achievement of sustainable outcomes, as firms involve them in the decision-making process and in performing activities oriented toward sustainability principles. One interesting aspect visible in the findings is that, despite various actors' multiple goals and motives, the quality of life emerges as the ultimate outcome of service ecosystems incorporating sustainability. An important mechanism in achieving this ultimate goal-higher quality of life-is relationship building and partnerships between the actors, as firms stressed in their communications when dealing with the issues of local communities. This perspective arises especially important in the present moment, in regards to the COVID-19 pandemic, when quality of life is especially affected.

In terms of resource integration, the previous framing offered by scholars of multiple resources integrated by actors [37] aimed at incorporating sustainability into service ecosystems [38] is expanded because resource integration is driven by an orientation toward the future. Indeed, actors are willing to participate in the resource integration processes because they feel the need to help establish different ways of thinking and to act in favor of sustainability, regarded as the opportunities offered to future generations. Firms are aiming at a sustainable future, and the participation of multiple actors in resource integration is pivotal because actors are expected to integrate their knowledge, their understanding of contexts, and their perspectives on complex issues. Similarly, resource integration plays its fundamental role in sustainable service ecosystems, as technological and intellectual resources are contributing to steer business models towards sustainability; this change occurs because resource integration takes place in new ways inspired by sustainability-driven goals. Furthermore, the findings show business models of firms excelling in sustainability as particularly interesting mechanisms of resource integration for service ecosystems incorporating sustainability. In this view, business models transcend the boundaries of a particular firm because they aim to configure value aimed at multiple actors, proposing offerings embedding different types of value, and developing innovative solutions aimed at sustainability, in partnership with other actors.

The findings also show resource integration as an innovation-inspiring process, as it aims to change how actors usually behave, due to the need to consider new challenges related to both contemporary and future-oriented issues. One interesting discrepancy between the literature and the empirical findings is the lack of social entrepreneurship initiatives in the latter. An explanation is that the data set consisted of sustainability reports of for-profit entities. This lack is worth further investigation. 
Furthermore, in a sustainability discourse, service exchange is framed as the result of a commitment to achieving best practices as a means of making supply chains sustainable apart from attaining sustainable outcomes. This is a relevant change compared to the standard logics on service exchange, as this vision moves beyond the 'economic motive' for interactions [39] and identifies how the benefits of other entities can be achieved. However, as the extant literature expanded the understanding of service to include both human-made service and natural services, the latter is lacking in the empirical findings. This is rather surprising, considering the increased focus on the environmental component of sustainability. One explanation to this discrepancy may be the inherent balance between the economic, social and environmental sustainability present in service ecosystems incorporating sustainability. Furthermore, main mechanisms of service exchange in service ecosystems incorporating sustainability are interactions and cooperation of multiple actors, and sustainability frames these interactions and cooperations. This advances the theoretical perspective proposed by Luu [42], who stated that service exchange is affected by an orientation to social goals, though the embeddedness of social-inspired values occurs further beyond operations. Indeed, companies showed how social orientation affects not only the way actors do business but also the way they live. Thus, actors are not simply partnering in efforts to promote sustainability; they are also actively promoting them.

The findings confirm that CSR, ethics and sustainability are the main institutions of service ecosystems incorporating sustainability. However, formalized and formal institutions in the form of laws, regulations, standards, certificated, and guidelines arise as especially relevant to legitimize the actions of these firms. Moreover, these formal institutions are assembled into institutional arrangements together with informal institutions such as organizational culture. In these arrangements, the three institutions of CSR, ethics and sustainability become supra-arrangements because they act as common denominators between the formal and informal institutions. Therefore, the institutional arrangements are permeated by sustainability, as proposed by Bridges [49], and inspire the value co-creation process, as a path toward multiple outcomes, compatible and not contrasting with financial results. To that end, a balance between financial outcomes, social results, and value as the consequences of use for multiple actors is the way to summarize what is sought by actors-both firms and other entities.

With regard to the value co-creation process, scholars have already highlighted the orientation toward multiple outcomes, including sustainability [51], which has led some authors to advocate for an environment-dominant logic [28]. The evidence from our research expands the understanding of social value, as it is now framed in each actor's domain; therefore, value co-creation heads toward sustainability due to actors' perceptions of, and assignment of meaning to, what they experience. Furthermore, actors do care about what other entities may benefit from in the future; thus, they express a future-oriented view leading to sustainability, namely, preserving future conditions for value co-creation. Accordingly, the multiple outcomes of value co-creation cannot be separated from one another and this leads to consider economic, social, and environmental value co-created as parts of a unique outcome; anyhow, these types of value should be balanced because of the vision of sustainability featuring the service ecosystem.

Concerning advances in the combination of SDL elements toward the achievement of sustainable value, we identified multiple overlaps among the elements in the debate over sustainability. These overlaps are inherent for the SDL narrative [45]. Nevertheless, it is interesting to observe this interplay within a sustainability-oriented discourse. Indeed, the vision and actions of firms toward sustainability are all related to more than a single element, thus moving to the empirical side the observation of the narrative of SDL and contributing to the debate launched by Vargo and Lusch [45], expanding the previous understanding of how single elements-such as resource integration [21] and value co-creation $[15,28]$ - may lead to sustainable value outcomes. Resource integration occurs based on actors' cultural and personal orientation toward sustainability, not only because of their role as resource integrators; therefore, actors' commitment drives resource integration toward sustainable goals and outcomes. In a similar vein, actors' commitment to sustainability permeates service exchange, representing the reason why service exchange takes place and how it favors the search for actors' 
benefits; in more detail, the benefits that actors aim to achieve through service exchange are not just for self but also for others, as concerns about future generations determine the way actors behave. Thus, the role of actors affects the service domain on a wider scale, as their personal values may affect the value co-creation process, as well as influence the institutions framing the context. Similarly, the role of actors in value co-creation processes oriented toward sustainability is further described, in line with Jurietti et al. [34]; their effect on institutions leads to change and describes how value co-creation occurs with an orientation toward sustainability. More relationships can be observed starting from resource integration; indeed, the integrated resources support the performing of service exchange toward sustainability, as both resource integration and service exchange are driven by sustainability-oriented purposes brought forth by actors. This expands the variety of resources brought by actors, and particularly the role of intangible resources such as trust and social capital, already proposed in the literature [37]. Additionally, resource integration itself takes place via a combination of efforts to achieve sustainable goals. Thus, actors embed their personal values and beliefs in resource integration. Additionally, their value orientation and the efforts they consider as necessary due to future-related concerns change the institutions that are driving resource integration. Consequently, value co-creation results in the materializing of actors' efforts in integrating the resources considered as suitable-and further needed compared to what firms are calling for-to achieve sustainable goals in sustainable ways.

Finally, service exchange is guided by institutions, as sustainability adjusts the beliefs, norms, and values toward which actors are oriented. In a similar vein, because service exchange is driven by motives beyond the economic sphere, value co-creation would lead to outcomes other than just economic ones. This is a different focus compared to extant research, as sustainability has been seen as an outcome in SDL studies, but previous studies focused on how single elements of narrative affect sustainability as an outcome [42]. Thus, the evidence highlight how firms referred to the elements of SDL in describing their actions toward sustainability and offered fresh insights into how actors are involved in the achievement of sustainability-oriented goals, through a resource integration process inspired by a vision of the future and the chance to preserve the chance to create value for future generations.

\section{Theoretical and Practical Implications}

This research expands the understanding of service ecosystems incorporating sustainability. This paper is based on extant literature stemming from sustainability and related literature streams that involve SDL elements (e.g., actors [20], resource integration [30], service exchange [22], institutions and institutional arrangements [49], and value co-creation [26]), clarifying their interplay toward sustainable value outcomes in sustainable service ecosystems. The elements shaping the narrative of SDL have been observed both theoretically and empirically, based on the sustainability reports of 100 firms excelling in sustainability.

Firstly, in answering our first RQ (see Table 1), we identified the actors contributing to the configuring of a sustainable service ecosystem; these actors are a multitude of entities looking for a better quality of life and the challenges of sustainability require their participation; indeed, firms are referring more and more to local communities, as well as to international partners, in a way that widens the idea of resource integration towards sustainable resource integration. The SDL literature stressed the role of multiple actors in the achievement of sustainability [20,22], and their commitment depicts their participation, driven by their personal values. Similar considerations may be offered with reference to culture, as actors' culture drives their behavior; this evidence only partially overlaps with values, as culture is becoming, for two reasons: namely, the increased awareness of actors toward sustainability and the efforts that firms make to spread a sustainability-oriented culture. Additionally, the empirical evidence offers an additional issue, namely, the role of actors themselves-mainly firms-in building relationships and partnerships to shape a proper context that favors sustainability. Moreover, value outcomes are oriented by actors' values, as in Williams and Aitken [35], though it would 
be myopic to consider actors as influencers of value creation processes through their values, as they are involved in, and committed to, the spreading of sustainable-oriented values and the performing of sustainability-inspired activities. A cornerstone of considering actors' orientation, their participation in value co-creation processes, and commitment toward sustainable goals is 'balance'; 'balance' means the conditions representing why firms are stressing how activities should be based on the participation of multiple actors in the decision-making process, because a business is sustainable if all actors can get something out of it, both for themselves directly as well as for future generations.

Secondly, we investigated mechanisms and drivers of resource integration, paying attention to the contribution offered by social capital and trust [37], as well as innovation as the result of a multi-actor process [36]. The main question on which we focused in regard to resource integration is how this process takes place. Novel solutions, also inspired by technology, are the main drivers of the way resources are integrated toward sustainability-inspired outcomes. The wider set of concerns, the multiple actors approach, and the need to unleash creativity are also key drivers of the resource integration process. Additionally, creativity embeds actors' support in terms of their knowledge about, and their feeling toward, sustainability; thus, innovation is increasingly a participative process based on resource integration that steers firms' activities toward a sustainable future. This consideration mirrors the previous understanding of service exchange as proposed by Wolfson et al. [44] about these efforts to attain sustainability. Indeed, firms are stressing how the participation of multiple actors in processes such as resource integration, as well as in service exchange and value co-creation, is based on priorities. These priorities depend on actors' orientation toward sustainability and drive their choices in integrating resources, joining the service exchange, and contributing to value co-creation.

Furthermore, as regards service exchange, the main aim transcends the economic motive, as in previous studies (e.g., [39]) depending on the expected benefits. This concept greatly affects the service exchange from a sustainable perspective because benefits are no longer regarded as something only for self, as actors consider what other entities, including future and yet-unknown generations, may get out of the resources. Indeed, actors cooperate in service exchange based on their own values; therefore, future-oriented values and the derived vision show that service exchange occurs through this cooperation. The latter is useful to debate in terms of the intertwining with actors' alignment and institutions, enriching the debate at two different levels. On the one hand, actors participate in service exchange-and the value co-creation process-if they perceive the potential outcomes as aligned with their values, and with other actors' values, too. On the other hand, these values flow into institutions and may change due to iterative institutional arrangements. Societies' concerns act in this way because they modify the existing institutions toward new ones oriented toward sustainability.

The sharing of ways of doing and perspectives on sustainability may be achieved if actors are aligned with specific goals. This issue has already been presented with reference to service exchange and deals in particular with institutions; indeed, scholars focused on institutions and institutional arrangements (e.g., $[47,49]$ ) describing the orientation and priorities attributed to sustainability itself as an institution permeating some value co-creation contexts and processes. Evidence shows how firms are doing their best so that more actors become committed to sustainability, as this would lead to an alignment in terms of value stimulating resource integration for sustainability. These efforts are evident in reports issued by firms, aimed at actors' involvement and continuing with the sharing of standards and principles as well as with the communicating of the results of firms' actions through sustainability reports. These efforts all converge on the definition of a sustainable value co-creation process that should give viability and sustainable development to the firm. This is in line with previous studies (e.g., $[59,61])$ and is complemented by the combination of firms' various value orientations and by institutions favoring the combination of the other elements and the continuous update of actors' orientation, due to the pressure of societal challenges. These results provide an answer regarding which typologies of institutions are shaping a sustainable service ecosystem; indeed, the orientation toward sustainability is changing, as in the notion of arrangements; thus, actors are contributing to this change and to fine-tuning the orientation toward sustainable outcomes. This consideration may 
be combined through a balanced approach toward new initiatives, aimed at offering benefits to the plethora of actors in touch with a firm. In this vein, an additional crucial concept is 'future', as the consideration of actors' needs is not limited to the actors that can be concretely identified; indeed, future generations, while unknown, are driving efforts toward sustainability, as preserving resources and value co-creation opportunities is one more outcome of sustainability-oriented service exchange.

In summary, a multi-stakeholder perspective emerges as needed to drive sustainability in the value co-creation process. This can be mirrored in the extant literature dealing with service ecosystems $[14,28,42,49]$, though the involvement of actors should lead firms to consider their support from the conception of new ideas to their implementation, and then to communication, as this latter action would favor a higher awareness of what to do to attain sustainability and to forward institutions as being supportive of the viability of a service ecosystem. Through the recalling of the three notions we identified above (i.e., balance, priorities, future), it can be stated that sustainability permeates value co-creation, providing an answer regarding which typologies of value emerge from this research. Value co-creation emerges as a process changed because of the infusion of social responsibility, as the value aimed at being co-created is not just economic and not just for actors themselves; on the contrary, it is a value configuration addressing the needs of multiple actors, defined through a balance of these perspectives, and including even the needs of future generations. This is due to the search for a balance between a multitude of expected outcomes stemming from the variety of actors involved, considered more or less urgent because of priorities based on the values shaping institutions, and oriented toward the future, as resource integration, service exchange, and value co-creation processes cannot disregard the opportunity to obtain certain outcomes for future generations. Based on this consideration, we would encourage the advancement of this understanding through the implementation of the notion of bequest value, deriving from natural ecosystem studies (e.g., [71]) and representing the need to preserve potential use for future unknown users through non-use.

From a practical perspective, firms oriented toward sustainable outcomes should consider the value of involving actors in shaping new value creation processes and should refer to them not only as addressees of sustainable outcomes but also as contributors. Thus, users' involvement strategies should be drawn to benefit from actors' participation in firms' processes, such as in resource integration and in line with the aim of sustainable service provision. Therefore, managers should address firms' efforts to promote the entire service ecosystem, as actors may help shape suitable value propositions and embed social value in service exchange. Finally, with regard to institutions, firms should be able to convey a message of sustainability so that all actors pay attention to what is needed for the creation of balanced value, namely, a process combining value in terms of profitability with value in terms of sustainability, viz. social and environmental outcomes.

\section{Limitations and Further Research}

This research is based on evidence from the top 100 firms excelling in sustainability worldwide, according to Forbes. Therefore, the focus is on large firms as for-profit actors. This focus can represent a limitation of our approach because it does not include non-profit actors or small and medium-sized enterprises. For example, our findings about social entrepreneurship initiatives are incomplete, most probably due to the data set. Thus, more research about other kinds of actors, including non-profit actors and small and medium-sized enterprises, may offer additional insights. In more detail, results may be complemented with case research on specific firms from the data set; additionally, new insights may emerge through an analysis of not-for-profit actors, as their vision is fully oriented to achieving sustainable goals. We would not suggest quantitative studies, as the results offer content that researchers should obtain through personal interpretation.

With regard to methodology, our paper is based on a manual content analysis, which can be further developed using a mixed approach that combines the key findings from a software-aided (or computational) content analysis with the results already available, as suggested by Lewis et al. [72]. 
Further research may be oriented toward investigating actors' involvement and contribution to value co-creation processes through a multi-level approach (meta-, macro-, meso-, micro-level), as this approach greatly mirrors the variety of actors and how they are related to firms in achieving concrete goals. Additionally, relevant changes—such as the pandemic characterizing 2020 — can be considered to observe how actors' orientation to quality of life and to sustainable value creation may be different due to the related changes in resource integration, institutions, and service exchange.

Author Contributions: The work can be considered as the result of the joint effort of all the authors. The authors jointly conceived the conceptualization, structure, and the methodology of the article, and they have jointly performed the analysis. Later, each author handled some sections of the article. D.B. wrote the introduction, the theoretical overview, and methodology. A.D. wrote the findings and the limitations and further research. M.T. wrote the discussion and the implications. All authors have read and agreed to the published version of the manuscript.

Funding: This research was partially funded by HELGE AX: SON JOHNSONS STIFTELSE and by ÅKE WIBERGS STIFTELSE (grant number H17-0200). Danilo Brozović wishes to thank the funders for their generous donations, which made this study possible.

Acknowledgments: The authors would like to thank the three anonymous reviewers for providing useful insights that helped us improve this paper and clarify some issues about the interplay between sustainability and SDL.

Conflicts of Interest: The authors have no conflicts of interest to declare.

\section{References}

1. United Nations. Overview of the UN Global Compact; United Nations: New York, NY, USA, 2014; Available online: https://www.unglobalcompact.org/ParticipantsAndStakeholders/business_associations. html (accessed on 20 December 2019).

2. United Nations. 2030 Agenda for Sustainable Development; United Nations: New York, NY, USA, 2019; Available online: https://sustainabledevelopment.un.org/post2015/transformingourworld (accessed on 20 December 2019).

3. Torres-Rahman, Z.; Baxter, G.; Rivera, A.; Nelson, J. Business and the United Nations: Working Together towards the Sustainable Development Goals: A Framework for Action; Harvard Kennedy School CSR Initiative and Inspiris Limited: Cambridge, MA, USA, 2015.

4. European Commission. Sustainable Development in the European Union; European Commission: Brussels, Belgium, 2019; Available online: https:/ec.europa.eu/eurostat/documents/4031688/9925908/KS-02-19-166EN-N.pdf/e985fa37-b510-4cae-b30e-c247989163d9 (accessed on 20 December 2019).

5. Brundtland, G.H.; Khalid, M.; Agnelli, S.; Al-Athel, S.; Chidzero, B. Our Common Future; The World Commission on Environment and Development, Oxford University Press: New York, NY, USA, 1987; Volumes 1-9.

6. Forbes. The Most Sustainable Companies in 2019. 2019. Available online: https://www.forbes. com/sites/karstenstrauss/2019/01/22/the-most-sustainable-companies-in-2019/\#1cb38c5f6d7d (accessed on 3 October 2019).

7. Stubbs, W.; Cocklin, C. Conceptualizing a "sustainability business model". Organ. Environ. 2008, 21, $103-127$. [CrossRef]

8. McDonagh, P.; Prothero, A. Sustainability marketing research: Past, present and future. J. Mark. Manag. 2014, 30, 1186-1219. [CrossRef]

9. Kolk, A. Corporate Social Responsibility in the Coffee Sector: The Dynamics of MNC Responses and Code Development. Eur. Manag. J. 2005, 23, 228-236. [CrossRef]

10. Gupta, S.; Kumar, V. Sustainability as corporate culture of a brand for superior performance. J. World Bus. 2013, 48, 311-320. [CrossRef]

11. Kemper, J.; Schilke, O.; Reimann, M.; Wang, X.; Brettel, M. Competition-motivated corporate social responsibility. J. Bus. Res. 2013, 66, 1954-1963. [CrossRef]

12. Laczniak, G.R.; Santos, N.J. The integrative justice model for marketing to the poor: An extension of SD logic to distributive justice and macromarketing. J. Macromark. 2011, 31, 135-147. [CrossRef]

13. Singh, R.; Shankar, R.; Shamah, R.A. Innovation within green service supply chains for a value creation. J. Model. Manag. 2012, 7, 357-374. 
14. Vargo, S.L.; Lusch, R.F. Service-dominant logic 2025. Int. J. Res. Mark. 2017, 34, 46-67. [CrossRef]

15. Lacoste, S. Sustainable value co-creation in business networks. Ind. Mark. Manag. 2016, 52, 151-162. [CrossRef]

16. Polese, F.; Botti, A.; Grimaldi, M.; Monda, A.; Vesci, M. Social innovation in smart tourism ecosystems: How technology and institutions shape sustainable value co-creation. Sustainability 2018, 10, 140. [CrossRef]

17. Rupo, D.; Perano, M.; Centorrino, G.; Vargas-Sanchez, A. A framework based on sustainability, open innovation, and value cocreation paradigms-a case in an Italian maritime cluster. Sustainability 2018, 10, 729. [CrossRef]

18. Barile, S.; Grimaldi, M.; Loia, F.; Sirianni, C.A. Technology, Value Co-Creation and Innovation in Service Ecosystems: Toward Sustainable Co-Innovation. Sustainability 2020, 12, 2759. [CrossRef]

19. Carroll, A.B. The pyramid of corporate social responsibility: Toward the moral management of organizational stakeholders. Bus. Horiz. 1991, 34, 39-48. [CrossRef]

20. Maignan, I.; Ferrell, O.C.; Ferrell, L. A stakeholder model for implementing social responsibility in marketing. Eur. J. Mark. 2005, 39, 956-977. [CrossRef]

21. Yang, Y.; Han, H.; Lee, P. An exploratory study of the mechanism of sustainable value creation in the luxury fashion industry. Sustainability 2017, 9, 483. [CrossRef]

22. Löbler, H. Humans' relationship to nature-framing sustainable marketing. J. Serv. Mark. 2017, 31, 73-82. [CrossRef]

23. Vargo, S.L.; Akaka, M.A.; Vaughan, C.M. Conceptualizing value: A service-ecosystem view. J. Creat. Value 2017, 3, 117-124. [CrossRef]

24. Arvidsson, A. Ethics and value in customer co-production. Mark. Theory 2011, 11, 261-278. [CrossRef]

25. Vargo, S.L.; Lusch, R.F. The four service marketing myths: Remnants of a goods-based, manufacturing model. J. Serv. Res. 2004, 6, 324-335. [CrossRef]

26. Sebhatu, S.P.; Enquist, B. ISO 14001 as a driving force for sustainable development and value creation. TQM Mag. 2007, 19, 468-482. [CrossRef]

27. Khavul, S.; Bruton, G.D. Harnessing innovation for change: Sustainability and poverty in developing countries. J. Manag. Stud. 2013, 50, 285-306. [CrossRef]

28. Polonsky, M.J. Transformative green marketing: Impediments and opportunities. J. Bus. Res. 2011, 64, 1311-1319. [CrossRef]

29. Abela, A.V.; Murphy, P.E. Marketing with integrity: Ethics and the service-dominant logic for marketing. J. Acad. Mark. Sci. 2008, 36, 39-53. [CrossRef]

30. Edvardsson, B.; Enquist, B. Quality improvement in governmental services: The role of change pressure exerted by the "market". TQM Mag. 2006, 18, 7-21. [CrossRef]

31. Haase, M. Values-based Value Creation and Responsibility-On the Relationship of "Doing Business" and “Doing CSR". Z. Wirtsch. Unternehm. 2015, 16, 339-368. [CrossRef]

32. Peloza, J.; Shang, J. How can corporate social responsibility activities create value for stakeholders? A systematic review. J. Acad. Mark. Sci. 2011, 39, 117-135. [CrossRef]

33. Nair, S.R.; Little, V.J. Context, culture and green consumption: A new framework. J. Int. Consum. Mark. 2016, 28, 169-184. [CrossRef]

34. Jurietti, E.; Mandelli, A.; Fudurić, M. How do virtual corporate social responsibility dialogs generate value? A case study of The Unilever Sustainable Living Lab. Corp. Soc. Responsib. Environ. Manag. 2017, 24, 357-367. [CrossRef]

35. Williams, J.; Aitken, R. The service-dominant logic of marketing and marketing ethics. J. Bus. Ethics 2011, 102, 439-454. [CrossRef]

36. Özçağlar-Toulouse, N.; Béji-Bécheur, A.; Murphy, P.E. Fair trade in France: From individual innovators to contemporary networks. J. Bus. Ethics 2009, 90, 589-606. [CrossRef]

37. De Chiara, A. SD Logic and CSR: The management of social capital for the value creation in SMEs. JBM-J. Bus. Mark. Manag. 2012, 5, 137-153.

38. Barroso-Méndez, M.J.; Galera-Casquet, C.; Valero-Amaro, V.; Galán-Ladero, M.M. Private-Nonprofit Partnerships in the context of CSR: The importance of relationship learning. Responsib. Sustain. 2013, 1, 15-26.

39. Poels, G. The resource-service-system model for service science. In Proceedings of the International Conference on Conceptual Modeling, Vancouver, BC, Canada, 1-4 November 2010; Springer: Berlin/Heidelberg, Germany, 2010; pp. 117-126. 
40. Lusch, R.F.; Vargo, S.L.; O'brien, M. Competing through service: Insights from service-dominant logic. J. Retail. 2007, 83, 5-18. [CrossRef]

41. Meng, J. Sustainability: A framework of typology based on efficiency and effectiveness. J. Macromark. 2015, 35, 84-98. [CrossRef]

42. Luu, T.T. CSR and customer value co-creation behavior: The moderation mechanisms of servant leadership and relationship marketing orientation. J. Bus. Ethics 2019, 155, 379-398. [CrossRef]

43. Palakshappa, N.; Grant, S. Social enterprise and corporate social responsibility: Toward a deeper understanding of the links and overlaps. Int. J. Entrep. Behav. Res. 2018, 24, 606-625. [CrossRef]

44. Wolfson, A.; Tavor, D.; Mark, S. CleanServs: Clean services for a more sustainable world. Sustain. Account. Manag. Policy J. 2014, 5, 405-424. [CrossRef]

45. Vargo, S.L.; Lusch, R.F. Institutions and axioms: An extension and update of service-dominant logic. J. Acad Mark. Sci. 2016, 44, 5-23. [CrossRef]

46. Guitián, G. Service as a bridge between ethical principles and business practice: A Catholic social teaching perspective. J. Bus. Ethics 2015, 128, 59-72. [CrossRef]

47. Ferrell, O.C.; Crittenden, V.L.; Ferrell, L.; Crittenden, W.F. Theoretical development in ethical marketing decision making. AMS Rev. 2013, 3, 51-60. [CrossRef]

48. Murphy, P.E.; Öberseder, M.; Laczniak, G.R. Corporate societal responsibility in marketing: Normatively broadening the concept. AMS Rev. 2013, 3, 86-102. [CrossRef]

49. Bridges, E. Executive ethical decisions initiating organizational culture and values. J. Serv. Theory Pract. 2018, 28, 576-608. [CrossRef]

50. Seals, G. An ethics paradigm for the service organization. Am. Int. J. Soc. Sci. 2013, 2, 1-9.

51. de Brito, M.P.; Terzieva, L. Key elements for designing a strategy to generate social and environmental value: A comparative study of festivals. Res. Hosp. Manag. 2016, 6, 51-59. [CrossRef]

52. Normann, R.; Ramírez, R. Designing Interactive Strategy: From Value Chain to Value Constellation; John Wiley \& Sons: Hoboken, NJ, USA, 1998.

53. Korschun, D.; Du, S. How virtual corporate social responsibility dialogs generate value: A framework and propositions. J. Bus. Res. 2013, 66, 1494-1504. [CrossRef]

54. Babin, B.J.; James, K.W. Retailing and Value, Doing the Right Thing by Providing Value. In Food Retailing and Sustainable Development: European Perspectives; Emerald Publishing Limited: Bingley, UK, 2018; pp. 171-185.

55. Lusch, R.F.; Webster, F.E., Jr. A stakeholder-unifying, cocreation philosophy for marketing. J. Macromark. 2011, 31, 129-134. [CrossRef]

56. Mazzarella, F.; Mitchell, V.; Escobar-Tello, C. Crafting Sustainable Futures. The Value of the Service Designer in Activating Meaningful Social Innovation from within Textile Artisan Communities. Des. J. 2017, 20 (Suppl. 1), S2935-S2950. [CrossRef]

57. Tolkamp, J.; Huijben, J.C.C.M.; Mourik, R.M.; Verbong, G.P.J.; Bouwknegt, R. User-centred sustainable business model design: The case of energy efficiency services in the Netherlands. J. Clean. Prod. 2018, 182, 755-764. [CrossRef]

58. Ahen, F.; Zettinig, P. Critical perspectives on strategic CSR: What is sustainable value co-creation orientation? Crit. Perspect. Int. Bus. 2015, 11, 92-109. [CrossRef]

59. Echebarria, C.; Barrutia, J.M.; Aguado, I.; Apaolaza, V.; Hartmann, P. Capturing the benefits that emerge from regional sustainability networks: The Castile-La Mancha network of sustainable cities and towns. Pap. Reg. Sci. 2016, 95, S27-S49. [CrossRef]

60. Polese, F.; Carrubbo, L.; Bruni, R.; Maione, G. The viable system perspective of actors in eco-systems. TQM J. 2017, 29, 783-799. [CrossRef]

61. Polese, F.; Carrubbo, L.; Bruni, R.; Caputo, F. Enabling actors' viable behaviour: Reflections upon the link between viability and complexity within smart service system. Int. J. Mark. Bus. Syst. 2018, 3, 111-120. [CrossRef]

62. Patton, M.Q. Qualitative Research E Evaluation Methods: Integrating Theory and Practice, 4th ed.; Sage Publications Ltd.: Thousand Oaks, CA, USA, 2015.

63. Corporate Knights 2019 Global 100 Results. Overview of 2019 Global 100 Most Sustainable Corporations in the World Inzdex. Available online: https://www.corporateknights.com/reports/2019-global-100/2019-global100-results-15481153/ (accessed on 3 October 2019). 
64. Tantalo, C.; Caroli, M.G.; Vanevenhoven, J. Corporate social responsibility and SME's competitiveness. Int. J. Technol. Manag. 2012, 58, 129-151. [CrossRef]

65. Mayring, P. Qualitative content analysis. Companion Qual. Res. 2004, 1, 159-176.

66. Hsieh, H.F.; Shannon, S.E. Three approaches to qualitative content analysis. Qual. Health Res. 2005, 15, 1277-1288. [CrossRef]

67. Hussain, N.; Rigoni, U.; Orij, R.P. Corporate governance and sustainability performance: Analysis of triple bottom line performance. J. Bus. Ethics 2018, 149, 411-432. [CrossRef]

68. Holsti, O.R. Content Analysis for the Social Sciences and Humanities; Addison-Wesley: Reading, MA, USA, 1969.

69. Deacon, D. Yesterday's papers and today's technology: Digital newspaper archives and 'push button'content analysis. Eur. J. Commun. 2007, 22, 5-25. [CrossRef]

70. Eteokleous, P.P.; Leonidou, L.C.; Katsikeas, C.S. Corporate social responsibility in international marketing: Review, assessment, and future research. Int. Mark. Rev. 2016, 33, 580-624. [CrossRef]

71. Krutilla, J. Conservation reconsidered. Am. Econ. Rev. 1967, 57, 787-796.

72. Lewis, S.C.; Zamith, R.; Hermida, A. Content analysis in an era of big data: A hybrid approach to computational and manual methods. J. Broadcast. Electron. Media 2013, 57, 34-52. [CrossRef]

(C) 2020 by the authors. Licensee MDPI, Basel, Switzerland. This article is an open access article distributed under the terms and conditions of the Creative Commons Attribution (CC BY) license (http://creativecommons.org/licenses/by/4.0/). 